\title{
Experimental Study of Ice Accretion on S826 \& S832 Wind Turbine
}

\section{Blade Profiles}

\author{
Jia Yi Jin*, Muhammad Shakeel Virk \\ Arctic Technology \& Icing Research Group \\ Faculty of Engineering Science \& Technology \\ UiT - The Arctic University of Norway, 8505 Narvik. \\ *Email: jin.jiayi@uit.no
}

\begin{abstract}
To optimize the aerodynamic performance and reduce production losses of wind turbine operating in icing conditions, it is necessary to better understand the ice accretion physics along wind turbine blade. This paper describes a case study of ice accretion physics and its effects on aerodynamic performance of S826 and S832 airfoils for dry and wet ice conditions. Both these airfoils have different geometric characteristics and are suitable for horizontal axis wind turbine blade. Icing tunnel experiments are carried out at Cranfield University to understand and simulate the ice accretion on both profiles. Results show that difference in geometric characteristics of both airfoils affects the ice accretion and more complex ice shapes are observed in case of S832 profile compared to S826. Analysis show that ice thickness is higher in case of dry rime ice conditions as compared to wet ice, whereas more complex ice shapes are observed for wet ice conditions. Computational Fluid Dynamics (CFD) based numerical analysis are carried out to study the airflow and droplets behaviour and to estimate the aerodynamic performance of both clean and iced profiles. No numerical simulations of ice accretion are carried out. CFD analysis show a change in airflow behaviour for iced profiles which leads to a decrease in aerodynamic performance, when compared with the clean profiles.
\end{abstract}

*Jia Yi Jin -- Phone Number: (+47)90996183; Fax Number: (+47)76966259; Email Address: jin.jiayi@uit.no. 
The change in aerodynamics performance is higher for S832 than S826 particularly for wet ice conditions.

Keywords: S832 airfoil; S826 airfoil; Icing wind tunnel; CFD; Aerodynamics; Wind turbine.

\section{Introduction}

In recent years, wind energy in ice prone cold regions has gained more interest due to the availability of good wind resources, but atmospheric icing is considered as hindrance in proper utilization of these good wind resources. Accreted ice on wind turbine blade changes its geometric shape, which affects the aerodynamic performance and leads to the power production losses. ${ }^{1}$ In some cases, such losses have been reported to lead up to a $17 \%$ decrease in Annual Energy Production (AEP) and $20 \%$ to $50 \%$ in the aerodynamic performance. ${ }^{2}$ Growing interest in better utilization of good wind resources in ice prone cold regions highlights the need of better understanding of ice accretion physics and finding innovative technological solutions for wind turbines operation in icing conditions to reduce the Capital Expenditure (CAPEX) and the Operational Expenditure (OPEX). In order to make the wind energy competitive with energy from fossil fuels, there has been a growing trend in the wind industry to scale up the turbine size to improve energy captured by a single wind turbine and thereby bring down the cost of power generation by economies-of-scale factors. In recent years, the cost of wind turbine has dropped significantly, which shows that, "It has become more economical to install wind power plants than using fossil fuels". ${ }^{3}$ This trend also highlights the importance of better understanding of ice accretion physics for wind turbines operation in wind rich cold regions.

Atmospheric ice accretion on wind turbine blades mainly occurs due to the impingement of super-cooled water droplets, which may freeze on blade surface immediately or after a short 
delay. ${ }^{4}$ Ice accretion on wind turbine blade mainly occurs along leading edge, which affects the airflow and droplet behaviour and reduces its aerodynamic performance. ${ }^{5}$ VTT technical research centre of Finland conducted a study to estimate the performance losses due to ice accretion for NREL 5MW wind turbine and found a decrease of $27 \%$ in its performance due to ice accretion. ${ }^{6-7}$ Ice accretion depends on both operating and geometric characteristics of the wind turbine blade. On same operating conditions, blade profiles with different geometry will result in different accreted ice shapes. Most investigations about ice accretion effects on wind turbine aerodynamic performance has been performed by using ordinary wind tunnel with artificial ice templates attached. ${ }^{8}$ Results from icing wind tunnel are more accurate, but due to complex setup and higher experimental cost, not many icing tunnel studies has been carried out to simulate the ice accretion on wind turbine blade profiles. NASA has conducted many studies about ice accretion on aircraft wing profiles using icing tunnels from 1940 to 1960, which has provided a useful insight to researcher about ice accretion physics. ${ }^{9}$ In recent years, CFD based numerical simulations have also begun to play a significant role in simulating and determining the performance of wind turbine blade profiles under icing conditions. ${ }^{10-13}$

S- Family airfoils are designed by National Renewable Energy Laboratory (NREL) with a focus to use for different size of wind turbine blades. Due to good aerodynamic characteristics, $\mathrm{S}$ family airfoils are being used by wind turbine blade designers. For this study, analysis has been carried out using S826 \& S832 airfoils, which are suitable for horizontal axis wind turbine blades. NREL has performed a series of ordinary wind tunnel experiments to study the aerodynamic performance of different un-iced (clean) 'S family' (S825, S826, S830, S831, S832) airfoils. ${ }^{14-16}$ However, there is not any published data available about icing tunnel experimental study of these profiles. Researchers from Norwegian University of Science and Technology (NTNU) have performed CFD simulations and ordinary wind tunnel 
experimentation of S826 airfoil, where they first used CFD simulations to simulate the accreted ice shapes and then manufactured the ice templates to attached them with clean S826 airfoil to study the aerodynamic characteristics using ordinary wind tunnel. ${ }^{17-18}$

This paper presents an icing tunnel experimental study of ice accretion on S826 and S832 airfoils to better understand the ice accretion physics for dry and wet ice conditions and its effects on aerodynamic performance. Icing tunnel experiments are carried out at Cranfield University UK, whereas to study the airflow and droplets behaviour for iced and clean airfoils, CFD-based numerical study is performed using ANSYS-FENSAPICE-FLUENT, which also provided an insight of aerodynamic performance comparison for clean and iced profiles.

\section{Icing Tunnel Experimental Study}

\subsection{Experimental Setup}

The experimental study is carried out at the icing tunnel laboratory of Cranfield University (CU), $\mathrm{UK}^{19}$. Both profiles are manufactured with the span of $758 \mathrm{~mm}$ and the chord length of $500 \mathrm{~mm}$. The surfaces of these profiles are made of galvanized steel (VGAL.V.D ×SID+Z275) with average surface roughness of 1 microns. Icing wind tunnel facility at CU has test section size $(761 \times 761 \mathrm{~mm})$ and can create realistic icing conditions for Median Volume Diameter (MVD) ranging from 15-80 microns, Liquid Water Content (LWC) from 0.05-3 g/m $\mathrm{m}^{3}$ and air temperature from -30 to $+30{ }^{\circ} \mathrm{C}$. Figure 1 shows the schematic view of the experimental setup of icing tunnel with mounting of the blade profile. 

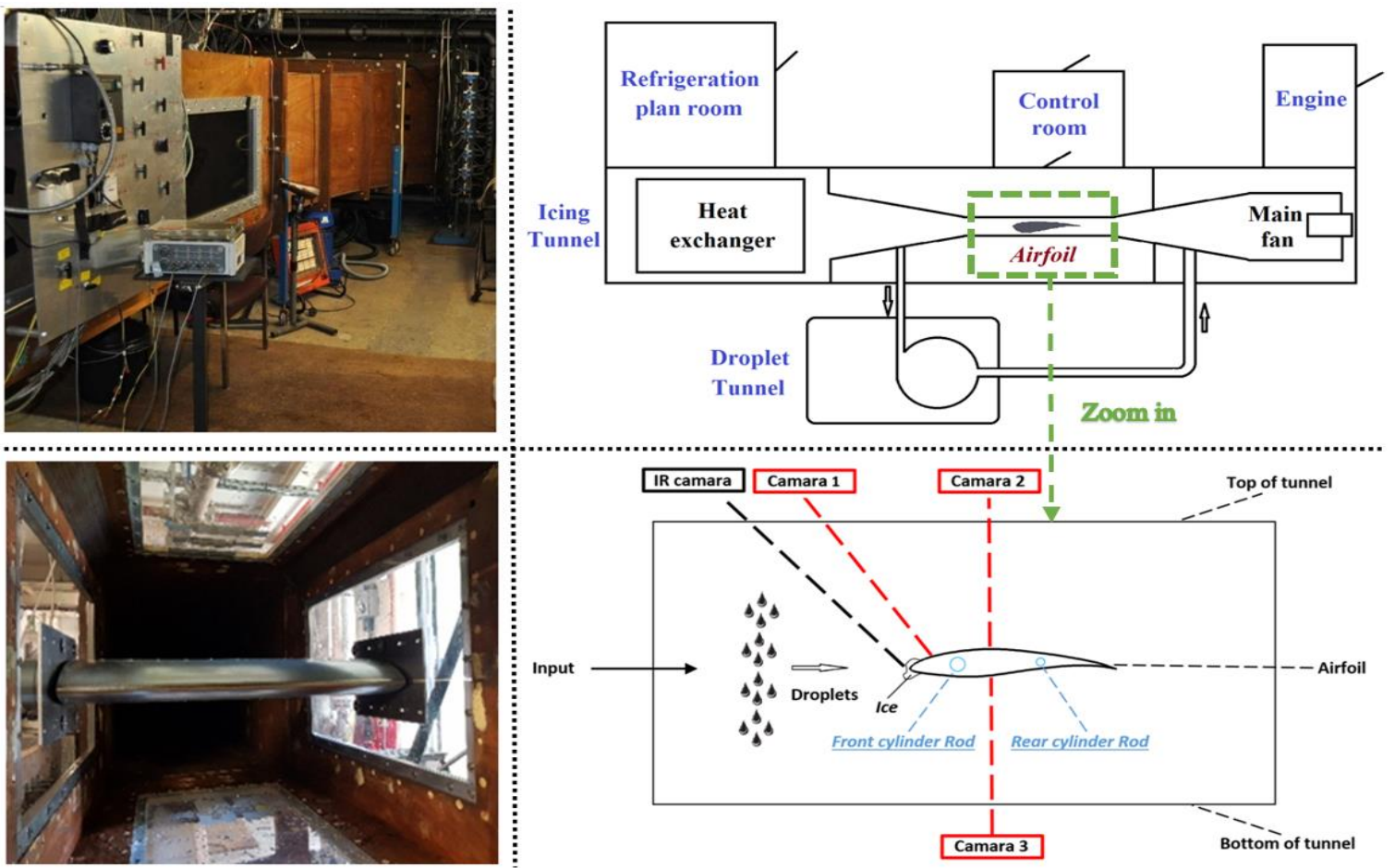

Figure 1: CU icing tunnel experimental setup.

To closely monitor the ice accretion along each profile, three High Definition ${ }^{4}$ cameras (two for side view and one from top view) are used for video recording and pictures. Accreted ice shapes are extracted and sketched manually after each experiment. These experiments are carried out at Reynolds number $=3 \times 10^{6}$ and angle of attack $(\mathrm{AOA})=0^{\circ}$ for both dry (rime) and wet (glaze) ice conditions. Table 1 presents the operating conditions used for this experimental study.

Table 1: Icing tunnel experimental conditions

\begin{tabular}{|c|c|c|c|c|c|c|c|c|}
\hline \multirow{2}{*}{ Airfoil } & Test & Ice Type & $\begin{array}{c}\text { Velocity } \\
(\mathbf{m} / \mathbf{s})\end{array}$ & $\begin{array}{c}\text { Temperature } \\
\left({ }^{0} \mathbf{C}\right)\end{array}$ & $\begin{array}{c}\text { LWC } \\
\left(\mathbf{g} / \mathbf{m}^{\mathbf{3}}\right)\end{array}$ & $\begin{array}{c}\text { MVD } \\
(\mathbf{m i c r o n s})\end{array}$ & $\begin{array}{c}\text { AOA } \\
(\mathbf{d e g r e e})\end{array}$ & $\begin{array}{c}\text { Time } \\
(\mathbf{m i n s})\end{array}$ \\
\hline \multirow{2}{*}{ S826 } & 1 & Wet & 77 & -5 & & & & \\
\cline { 2 - 6 } & 2 & Dry & 70 & -20 & \multirow{2}{*}{0.35} & 20 & 0 & 15 \\
\hline \multirow{2}{*}{ S832 } & 3 & Wet & 77 & -5 & & & & \\
\cline { 2 - 6 } & 4 & Dry & 70 & -20 & & & & \\
\hline
\end{tabular}


In order to better monitor the icing tunnel operation, various operating parameters of icing tunnel are also closely monitored to ensure the smooth operation. Droplet MVD of 20 microns is used with the droplet distribution spectrum consisting of 60 bins. Figure 2 shows the droplet distribution spectrum used for this study in addition to the variations in wind speed and total temperature at the icing tunnel test section for both dry and wet ice conditions.
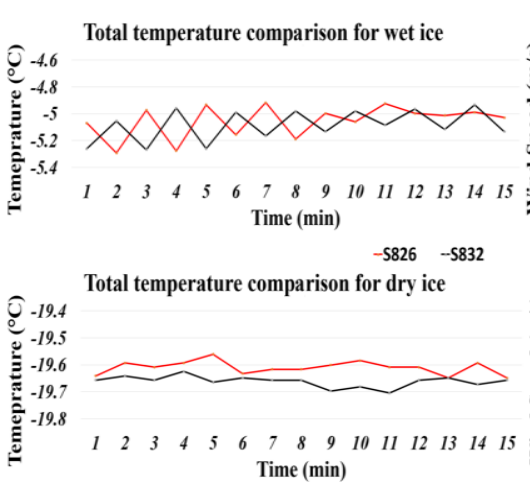

$-5826 \quad-5832$

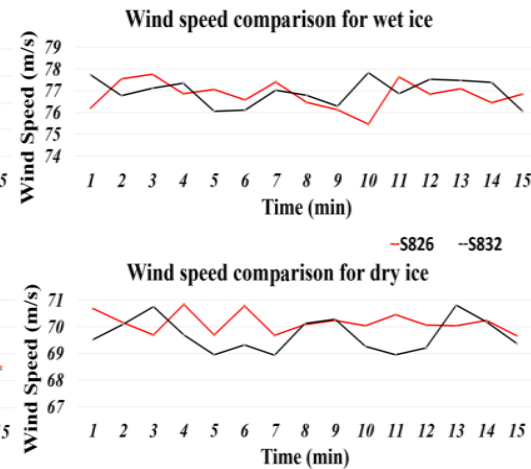

$-5826 \quad-5832$

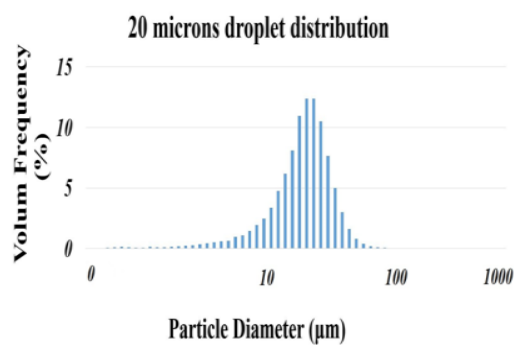

Particle Diameter $(\mu \mathrm{m})$

Figure 2: Icing tunnel operating conditions variation \& droplet distribution spectrum used.

\subsection{Experimental Results}

During each experiment, ice accretion was monitored from three different views using HD cameras. Figures $3 \& 4$ show the ice growth along both profiles for dry and wet ice conditions during the experimental time span.

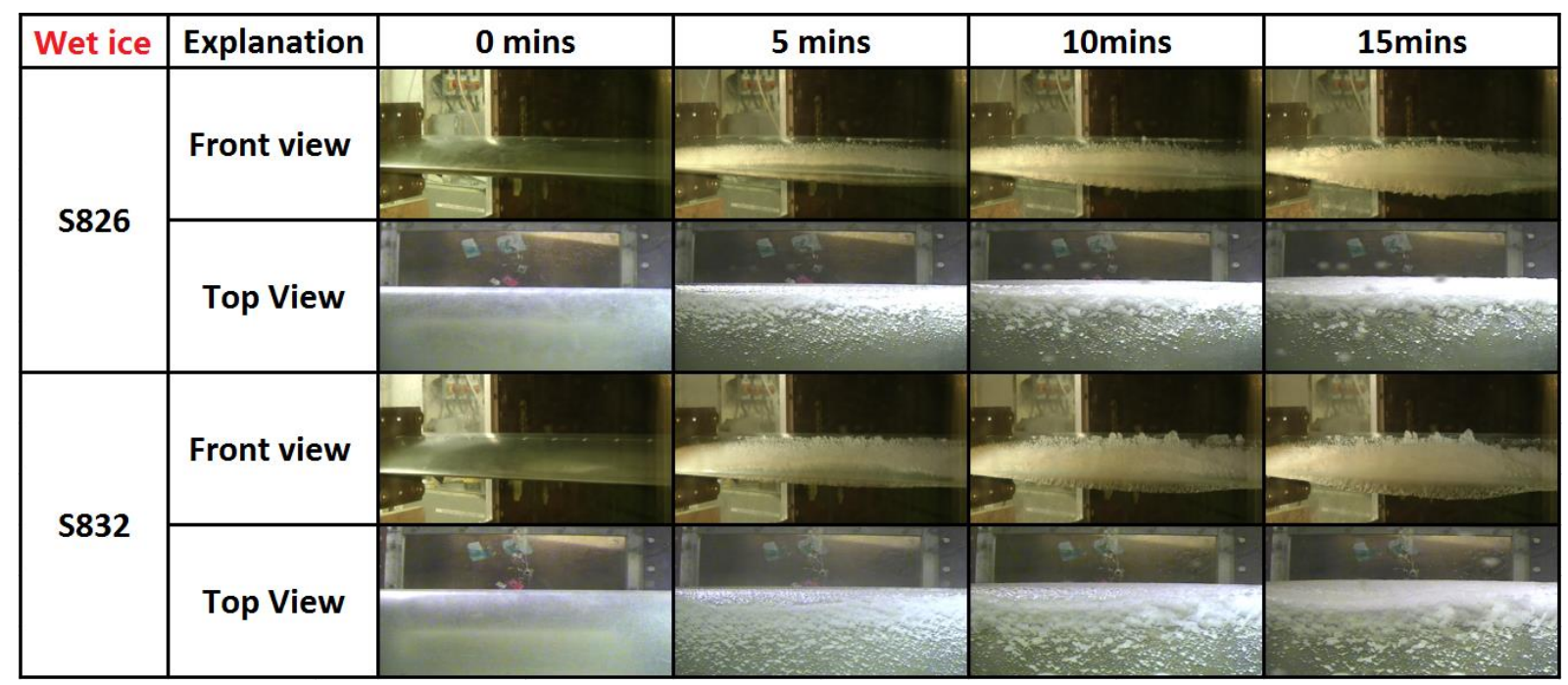

Figure 3: Overview of wet ice growth along S826 and S832 profiles. 


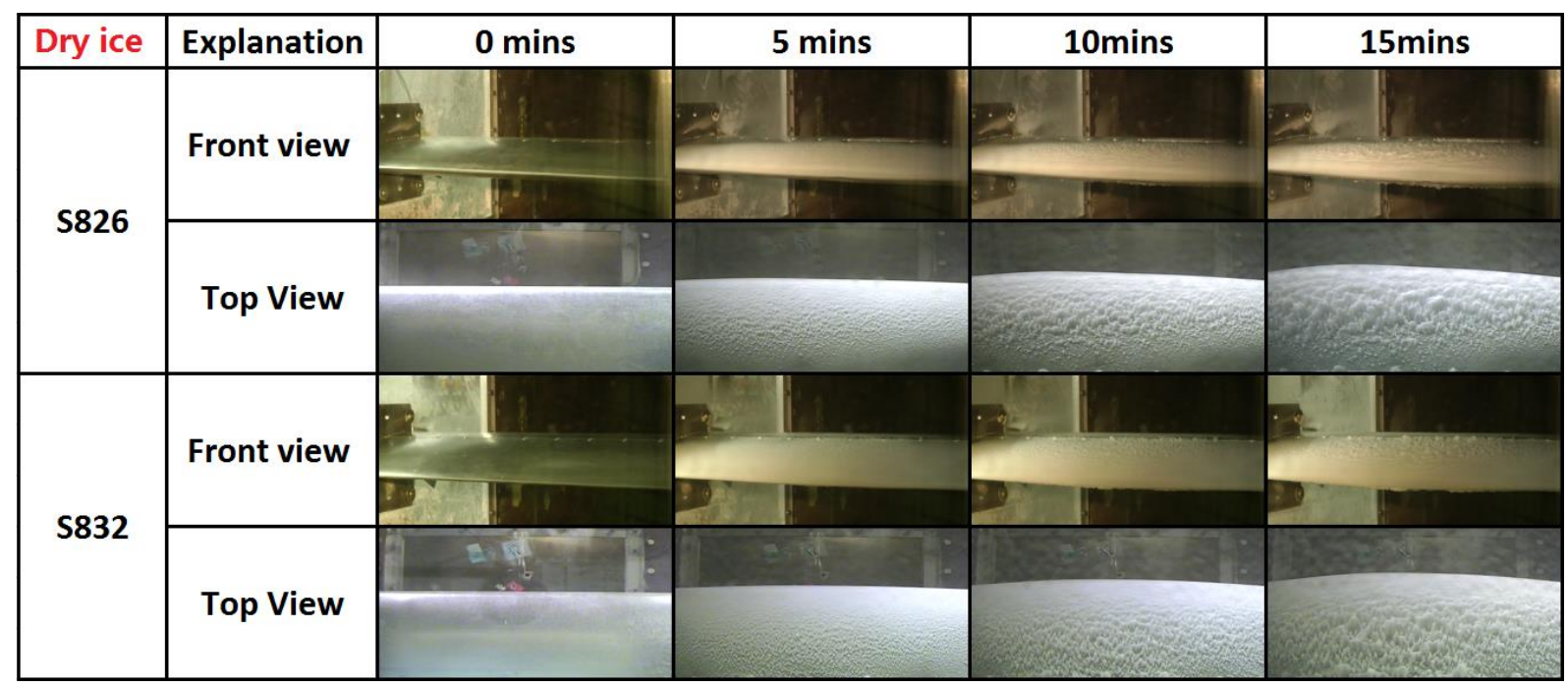

Figure 4: Overview of dry ice growth along S826 and S832 profiles.

To get the accreted ice shapes after each experiment, the ice chunks were cut from centre section of each profile. Figure 5 shows the cut-out cross section and resultant ice shape from each experiment. These ice shapes were sketched manually from each cut out on grid paper and then was digitalized using computer aided design software - SolidWorks.

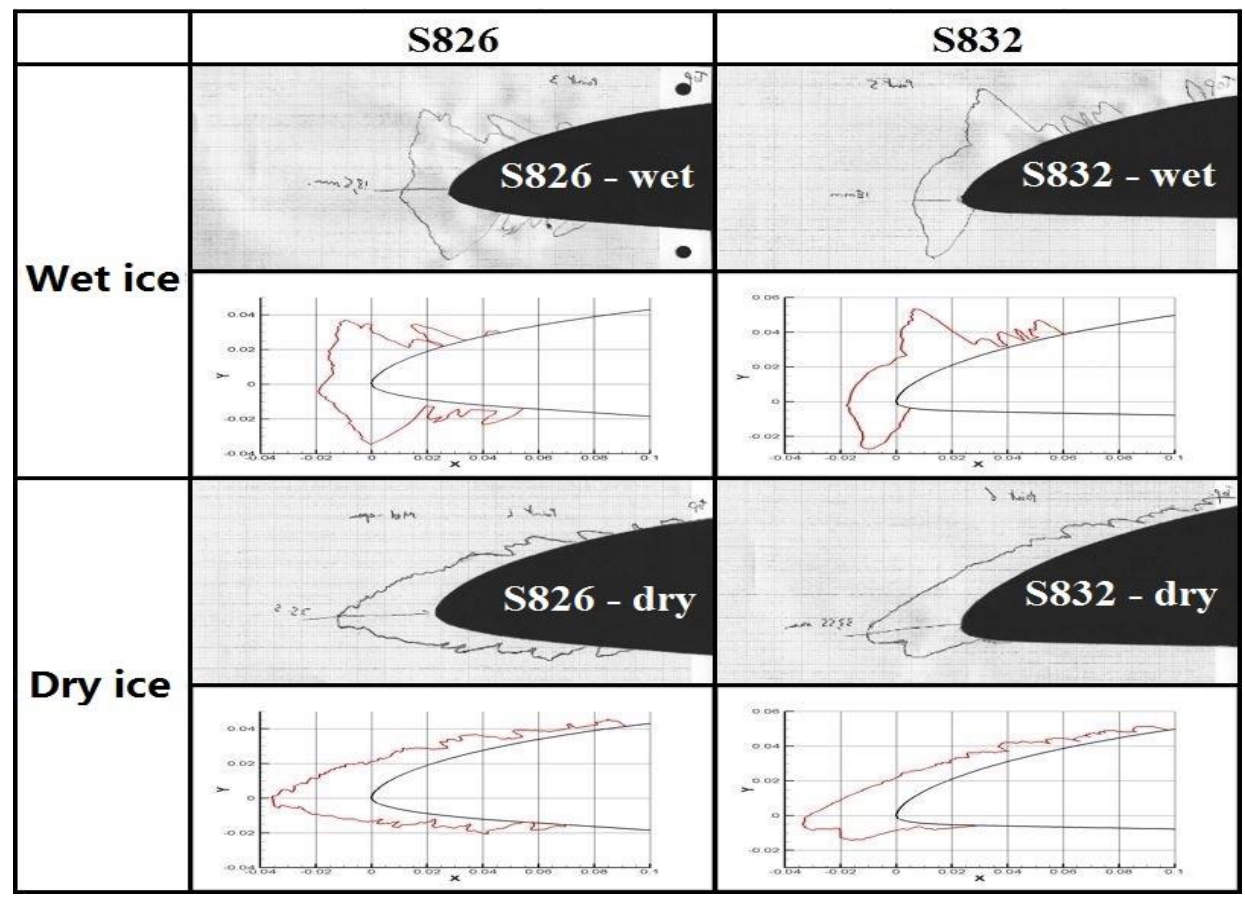

Figure 5: Experimental ice shapes for dry and wet ice conditions. 
Both these airfoils have different geometric shapes, where S826 has more curvature along pressure side, whereas in case of S832 pressure side is having very small curvature and looks almost flat. Due to difference in the geometric characteristics, accreted ice shapes and wetted surface area covered by ice along pressure and suction sides of both profiles is different. For both profile sections, ice mainly accreted along leading edge, but distribution of ice is different along pressure and suction sides. For S826, ice accretion is extended on both sides almost equally, where as in case of S832, ice is mainly accreted along suction side of the profile and very less ice is accreted along pressure side.

Large individual ice feathery spikes pointing perpendicular to the profile surface are observed. For S826 profile section, the feathery spikes of ice are concentrated, connected and densely packed with direction of feather growing parallel to the airflow, while for S832 airfoil, the feathery spikes are loosely connected to the direction of growth being perpendicular to the profile surface. Results show that for wet ice conditions, the ice shapes are more complex along leading edge when compared with the dry ice conditions. This is mainly due to the low freezing rate of the super cooled water droplets impinging along the profile surface. For wet ice conditions, high aerodynamic forces along stagnation line of the blade profile push the nonfreezing water droplets towards upper and lower sides of the profile surface, which resulted in horn shape ice along leading edge. For dry ice conditions, all impinged droplets freeze, which resulted in more streamlined ice shapes. For case of wet ice conditions, experimental results show that ice accumulation extended along chord length about 5\%-10\% for S826 profile and $15 \%-20 \%$ for S832 profile section, whereas for the dry ice conditions, ice accumulation extends towards the chord length approximately up to 25\% for both S826 and S832 profiles. To avoid side wall effects of icing wind tunnel, these measurements were taken from centre section of the blade profiles. Table 2 shows the maximum ice thickness for each profile. 


\begin{tabular}{|c|c|c|}
\hline \multirow{2}{*}{} & \multicolumn{2}{|c|}{ Max ice thickness (mm) } \\
\cline { 2 - 3 } & S826 & S832 \\
\hline Wet Ice & 18.5 & 18 \\
\hline Dry Ice & 35.5 & 33.55 \\
\hline
\end{tabular}

\section{Numerical Study}

CFD-based numerical analyses are carried out using ANSYS-FENSAPICE-FLUENT. The

objective of this numerical study is to analyse the airflow and droplet behaviour along clean and iced profiles obtained from icing tunnel experiments and study the aerodynamic characteristic. No numerical simulations of ice accretion are carried out. These CFD simulations provided an insight of the airflow and droplet behaviour, which was not easy to study from experiments. The numerical study of airflow behaviour is performed by solving nonlinear partial differential equations for the conservation of mass, momentum and energy.

$166 \frac{\partial \rho_{\alpha_{1}}}{\partial t}+\vec{\nabla}\left(\rho_{\alpha_{1}} \overrightarrow{\nu_{\alpha_{1}}}\right)=0$

$\frac{\partial \rho_{\alpha_{1}} \overrightarrow{\boldsymbol{v}_{\alpha_{1}}}}{\partial t}+\vec{\nabla}\left(\rho_{\alpha_{1}} \overrightarrow{\boldsymbol{v}_{\alpha_{1}}} \overrightarrow{\boldsymbol{v}_{\alpha_{1}}}\right)=\vec{\nabla} \cdot \sigma^{i j}+\boldsymbol{\rho}_{\alpha_{1}} \vec{g}$

$\frac{\partial \rho_{\alpha_{1}} E_{\alpha_{1}}}{\partial t}+\vec{\nabla}\left(\rho_{\alpha_{1}} \overrightarrow{\boldsymbol{v}_{\alpha_{1}}} H_{\alpha_{1}}\right)=\vec{\nabla}\left(\kappa_{\alpha_{1}}\left(\vec{\nabla} T_{\alpha_{1}}\right)+v_{i} \tau^{i j}\right)+\boldsymbol{\rho}_{\alpha_{1}} \vec{g} \overrightarrow{\boldsymbol{v}_{\alpha_{1}}}$

Where $\rho$ is the density of air, $\mathrm{v}$ is the velocity vector, subscript $\alpha_{1}$ refers to the air solution, $\mathrm{T}$ refers to the air static temperature in Kelvin, $\sigma^{i j}$ is the stress tensor, $\mathrm{E}$ and $\mathrm{H}$ are the total initial energy and enthalpy respectively. Two phase flow (air and water droplets) is simulated using the Eulerian approach, where super cooled water droplets are assumed to be spherical. The Eulerian two phase fluid model consists of the Navier-Stokes equation with the water droplets continuity and momentum equation. The water droplet drag coefficient is based on the empirical correlation for the flow around the spherical droplets described by Clift et al. ${ }^{20}$ 
$\frac{\partial \alpha_{2}}{\partial t}+\vec{\nabla}\left(\alpha_{2} \overrightarrow{V_{d}}\right)=0$

$\frac{\partial\left(\alpha_{2} \overrightarrow{V_{d}}\right)}{\partial t}+\vec{\nabla}\left(\rho_{\alpha_{2}} \overrightarrow{V_{d}} H_{d}\right)=\frac{C_{D} R e_{d}}{24 k} \alpha_{2}\left(\overrightarrow{V_{\alpha_{2}}}-\overrightarrow{V_{d}}\right)+\alpha_{2}\left(1-\frac{\rho_{\alpha_{2}}}{\rho_{d}}\right) \frac{1}{F r^{2}} \vec{g}$

$$
F r=\frac{u_{0}}{\sqrt{g_{0} l_{0}}}
$$

Where $\alpha_{2}$ is the water volume fraction, $\overline{V_{d}}$ is the droplet velocity, $\mathrm{C}_{\mathrm{D}}$ is the droplet drag coefficient and Fr is the Froude number, $\mathrm{u}_{0}$ is a characteristic flow velocity, $\mathrm{g}_{0}$ is in general a characteristic external field, and $l_{0}$ is a characteristic length. The numerical analyses are carried out using custom droplet diameters distribution spectrums used in CU icing tunnel for MVD = 20 microns.

Mesh sensitivity study was carried out using coarse, medium and fine meshes to accurately determine the boundary layer characteristics (shear stress and heat flux). During mesh sensitivity analysis, number of mesh elements and y+ value less than 1 for first cell layer was selected based upon the heat flux calculations, where a numerical check was imposed that the heat flux computed with the classical formulae dT/dn should be comparable with the heat flux computed with the Gresho's method. Mesh sensitivity study showed that the effect of mesh size on droplet solution was negligible, however some flow quantities including convective heat flux on the blade surface was sensitive to the mesh size. After mesh sensitivity analysis, $\mathrm{C}$ type structured numerical grid with approx. 75,000 grid cells was used. K-omega SST turbulence model is used as a compromise between acceptable computational cost and required accuracy for simulating the turbulent flow. Figure 6 shows the numerical grid of iced profiles used in this study. The numerical simulations are carried out at operating conditions specified in Table 3. 


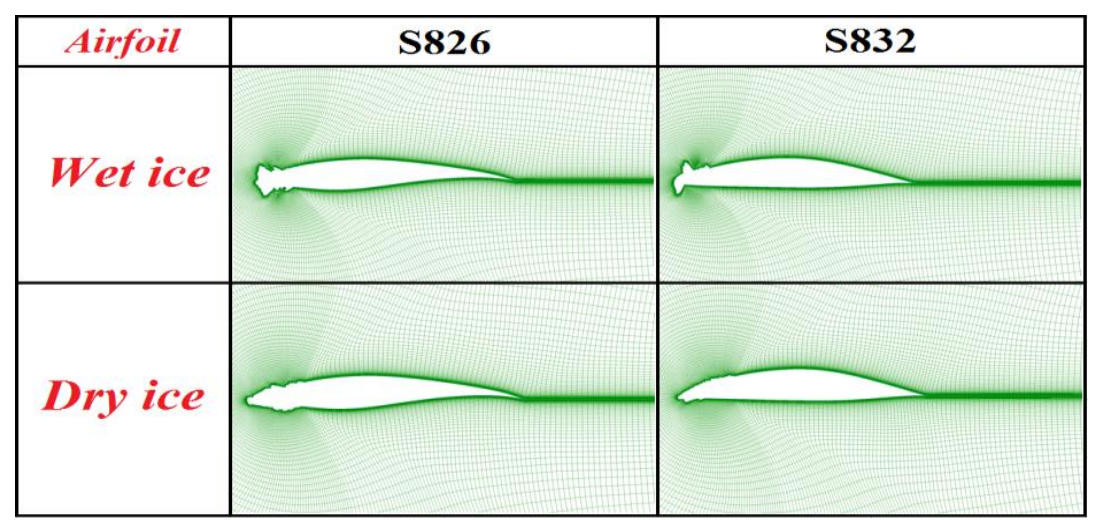

Figure 6: Numerical grid for iced S826 and S832 airfoils.

Table 3: Numerical setup

\begin{tabular}{|c|c|c|}
\hline Ice type & Wet ice & Dry ice \\
\hline Chord length (m) & \multicolumn{2}{|c|}{0.5} \\
\hline Angle of attack (degree) & \multicolumn{2}{|c|}{0} \\
\hline Air velocity (m/s) & 77 & -20 \\
\hline Temperature (Celsius) & -5 & 70 \\
\hline MVD (microns) & \multicolumn{2}{|c|}{0.35} \\
\hline Droplet distribution & Customer distribution from CU (see Figure 2) \\
\hline LWC $\left(\mathbf{g}^{\mathbf{m}} \mathbf{m}^{\mathbf{3}}\right)$ & \multicolumn{2}{|c|}{0.5} \\
\hline
\end{tabular}

\subsection{Numerical Results}

Ice accretion along each profile changes its geometric shape, which affects the flow behaviour along pressure and suction sides of the profile and results a change in its aerodynamic performance. In this study, CFD based numerical analysis are carried out to simulate the airflow behaviour using experimental iced profile shapes. Figure 7 shows the velocity streamlines for each case, where results show more complex flow separation for wet ice cases due to presence of ice horns along leading edge. For S826, the wet ice shape along leading edge is less complex as compared to S832, where a big ice horn is present at leading edge and ice is mainly accreted along the suction side. Due to such ice growth, airflow separation along S832 leading edge is more complex as compared to S826. 


\begin{tabular}{|l|c|c|}
\hline Airfoil & S826 & S832 \\
\hline \multirow{4}{*}{ Wet ice } & S826-Glaze & \\
\cline { 2 - 3 } & & \\
\cline { 2 - 3 } Dry ice & & \\
& & \\
& & \\
& & \\
& & \\
\hline
\end{tabular}

Figure 7: Velocity streamlines along iced profiles.

214 To understand the droplet behaviour along clean and iced profiles, numerical analysis are carried out to make a comparison of droplet collision efficiency. Droplet collision efficiency is the calculation of possibility of droplets impinging on the blade surface, as all droplets suspended in the air will not collide with the blade surface due to blade profile geometric features and flow behaviour. Droplet collision efficiency can be defined as the flux density of the droplets striking the surface in relation to the maximum possible. The numerical analyses are carried out using custom droplet diameters distribution spectrums used in CU icing tunnel for MVD $=20$ microns. Figure 8 shows the comparison of droplet collision efficiency along both profiles for clean and iced conditions, where a change in droplet behaviour is observed.
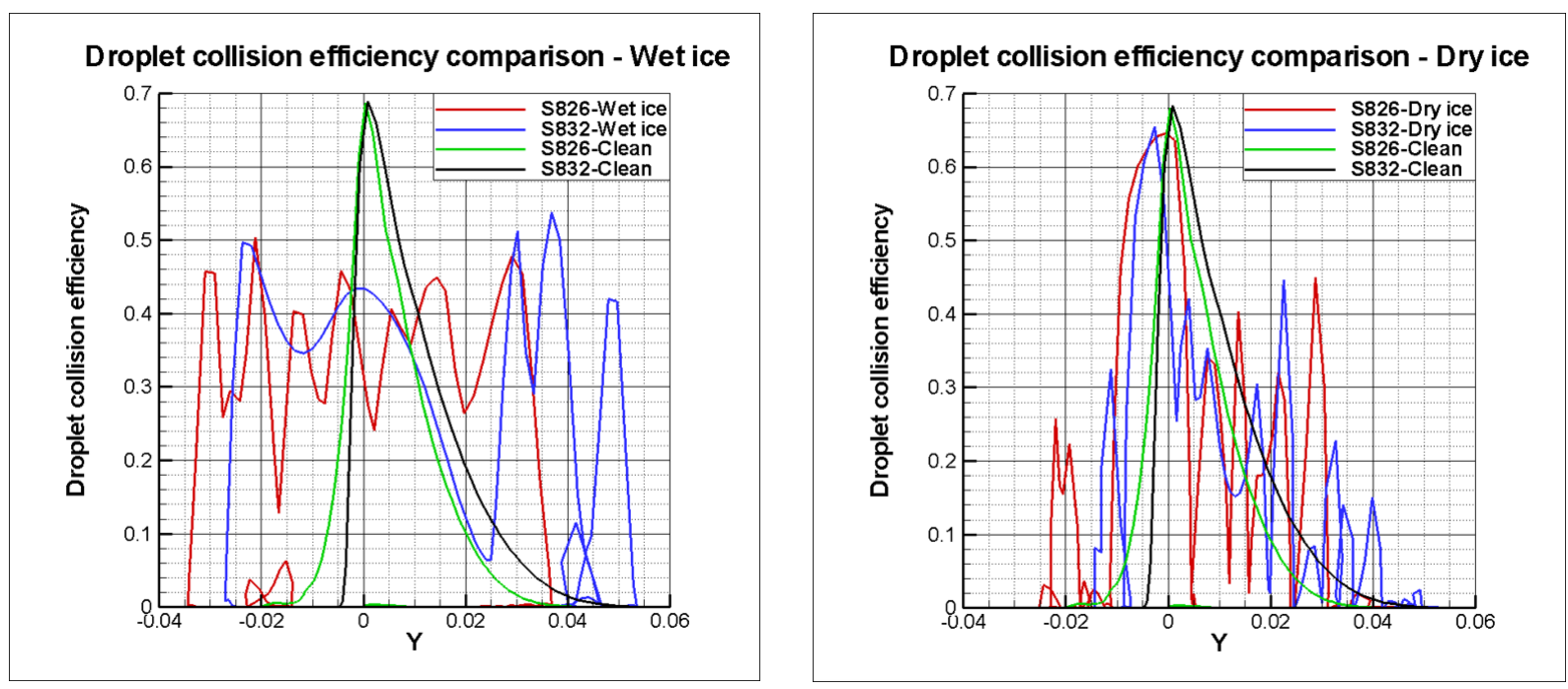

Figure 8: Droplet collision efficiency comparison. 
Results show a decrease in maximum droplet collision efficiency for iced profiles, where as an increase in the droplet impingement area is observed, when compared with the clean profile. This change in the droplet impingement behaviour is mainly due to change in profile geometric shape after ice accretion. Figure 9 presents a comparison of droplet impingement locations along clean and iced profiles. Results show an increase in the profile surface area under impingement of droplets in case of iced profiles.

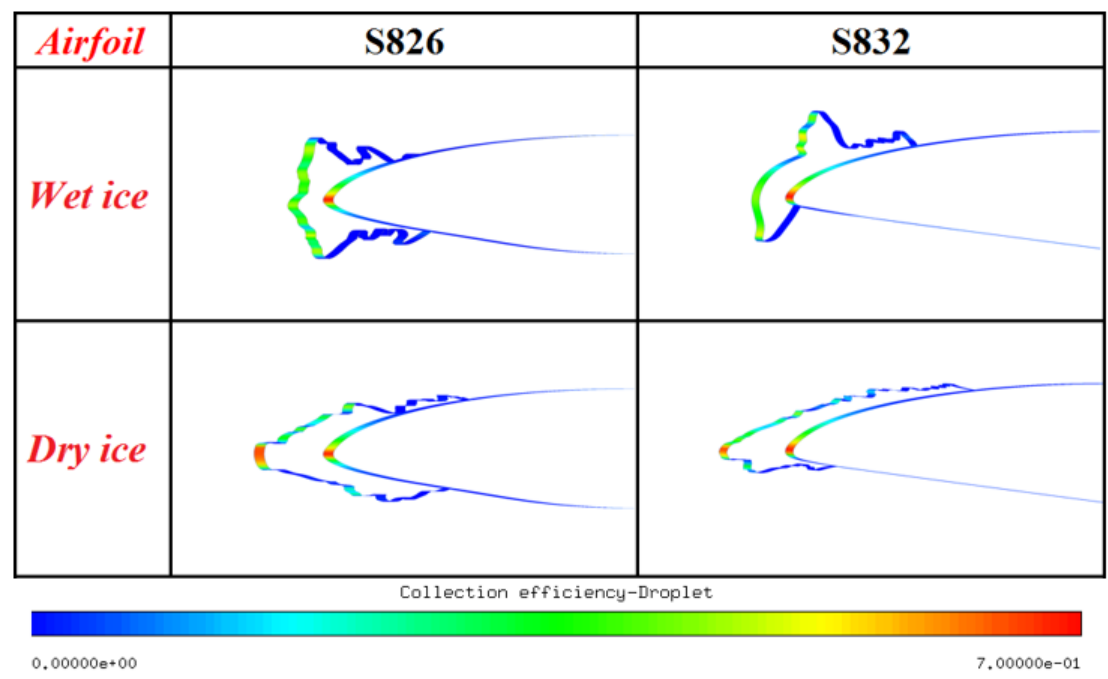

Figure 9: Droplet collision efficiency and impingement location along clean and iced profiles.

\subsection{Aerodynamic Performance Analysis}

To study the change in aerodynamics characteristics due to ice accretion, a detailed parametric numerical study is carried out using ANSYS-FLUENT. To validate the numerical setup, first the CFD simulations of clean S826 \& S832 are carried out to estimate the aerodynamic characteristics and results are compared with the published experimental NREL wind tunnel data of both airfoils. After that CFD simulations of airflow behaviour over ice profiles are carried out and aerodynamic charactsirtics are calculated and compared with the clean profile. The iced profile shapes obtained from experiments are used. Flow is simulated at different AOA's and comparison is made with the experimental aerodynamic characteristics of clean S826 and S832 airfoils. ${ }^{14-15}$. Figure 10 shows the aerodynamic coefficients of both clean and 
iced profiles, where experimental NREL clean represents the experimental results $\left(A O A=-5^{\circ}\right.$ to $10^{\circ}$ ) of clean profile ${ }^{14-15}$. Results show a decrease in lift coefficients and increase in drag coefficient for iced profiles. This change is more significant for wet iced profiles, because of higher flow separation due to complex accreted ice shapes along leading edge.

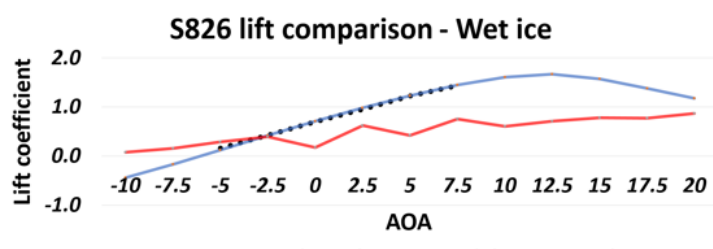

..Experimental NREL-Clean -Numerical-Clean -Numerical--ce

S826 drag comparison -Wet ice

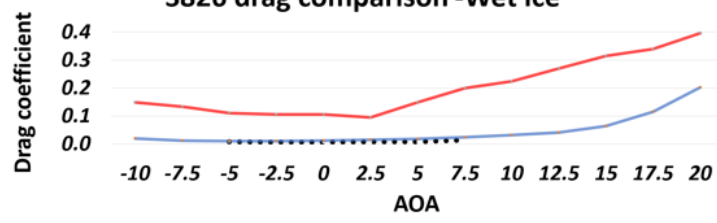

..Experimental NREL-Clean -Numerical-Clean -Numerical-Ice

S832 lift comparison - Wet ice

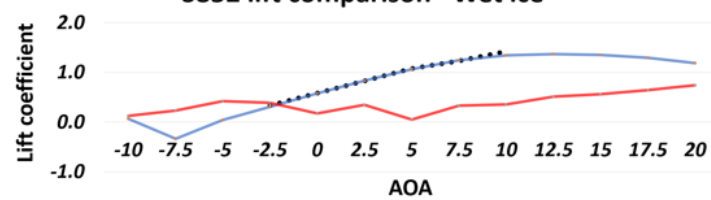

-.Experimental NREL-Clean -Numerical-Clean -Numerical-ke

S832 drag comparison -Wet ice

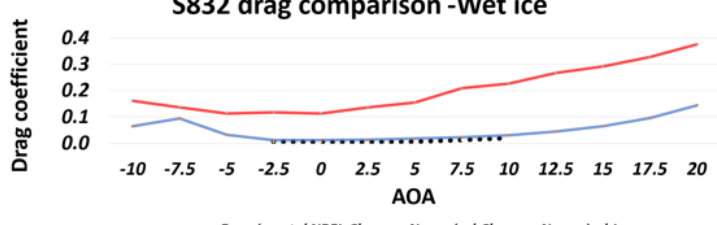

-.Experimental NREL-Clean -Numerical-Clean -Numerical-1ce

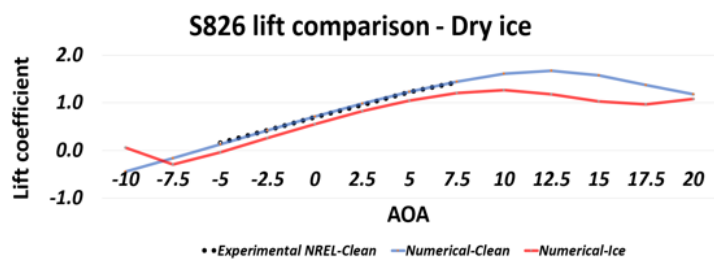

S826 drag comparison -Dry ice
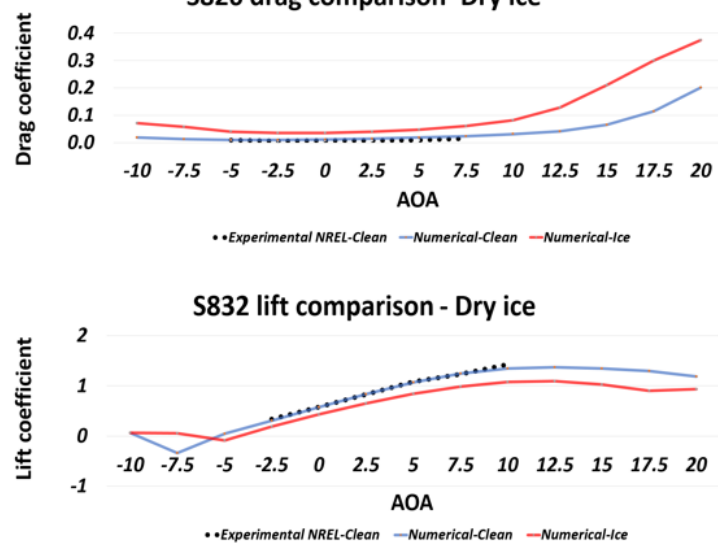

S832 drag comparison -Dry ice

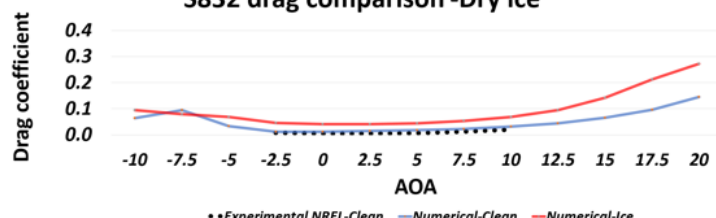

Figure 10: Comparison of aerodynamic performance for clean and iced profiles.

Figure 11 presents the pressure coefficients distribution along clean and iced profiles at $A O A=$ $-5^{\circ}, 0^{\circ} \& 5^{\circ}$. Results show that due to ice accretion along leading edge, the pressure coefficient of iced profile is quite different from clean profile. This change in pressure coefficient is more significant along leading edge and is quite dependant on accreted ice shape and distribution along pressure and suction sides. In case of wet ice more complex ice shapes are observed and the change in pressure coefficient is more significant. 

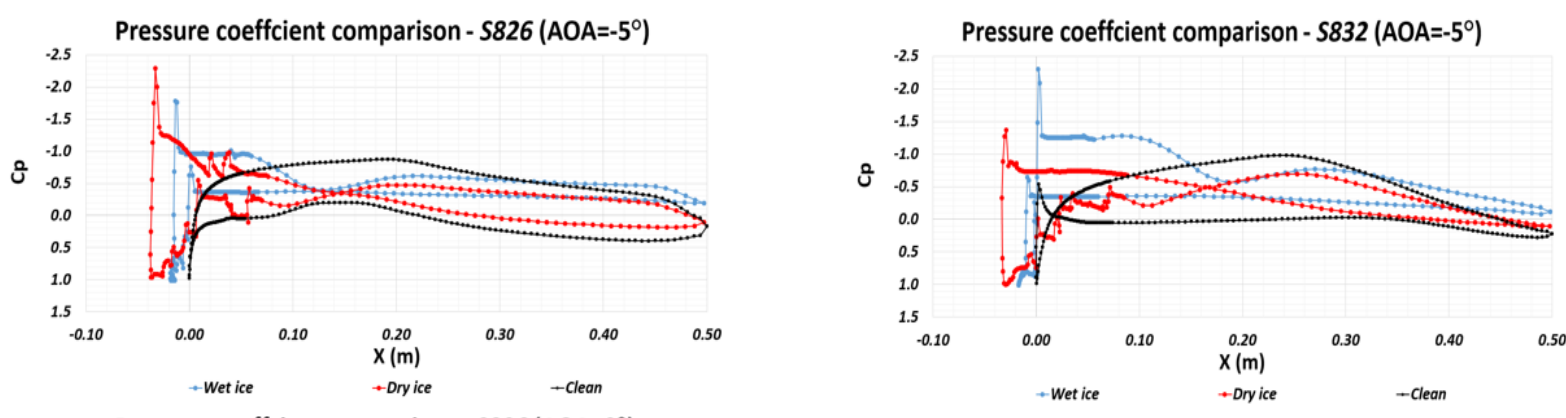

Pressure coeffcient comparison - $5826\left(\mathrm{AOA}=0^{\circ}\right)$
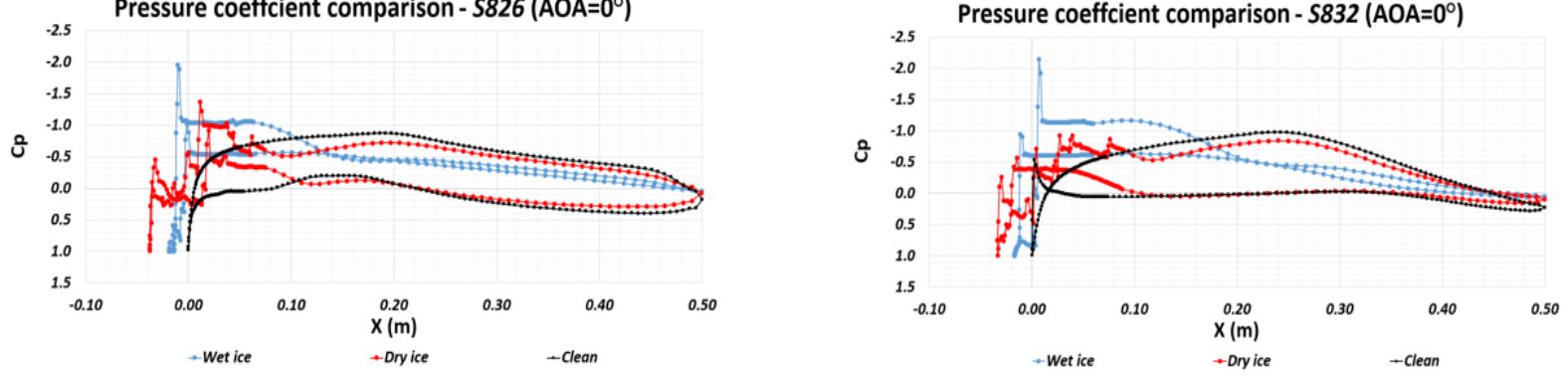

Pressure coeffcient comparison - $5826\left(\mathrm{AOA}=5^{\circ}\right)$
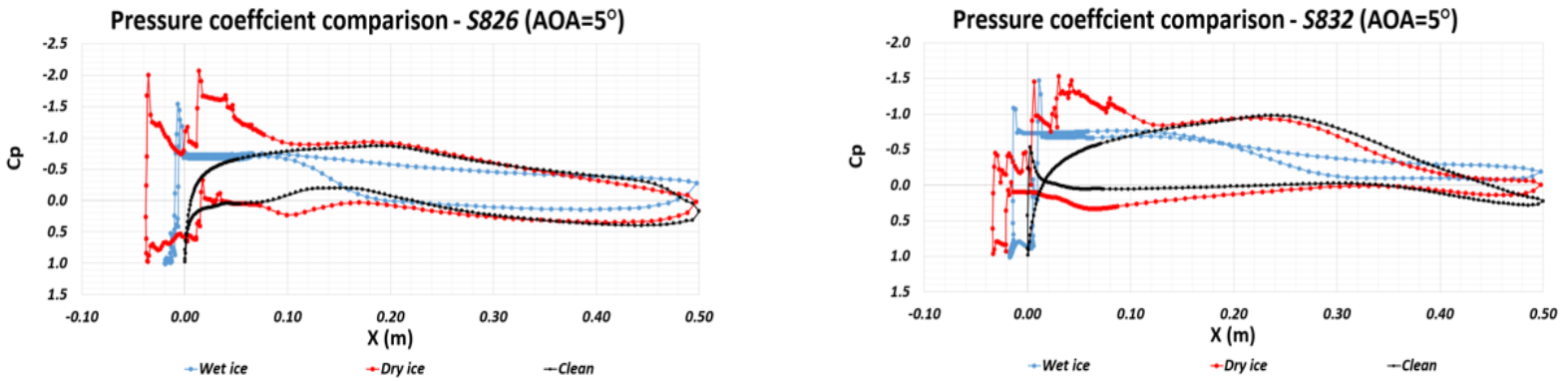

Figure 11: Pressure coefficient of clean and iced profiles at different AOA.

\section{Conclusion}

This study provides a good insight of ice accretion physics and its effect on aerodynamic performance of S826 \& S832 airfoils. Results show that ice accreted differently along both profiles due to different geometric features. More complex ice shapes are observed in case of S832 profile when compared with S826. Horn type complex ice shapes are observed for both profiles in case of wet ice conditions mainly due to low freezing fraction and higher water run back. Analysis show that accreted ice distribution along pressure and suction sides of both profiles is different. In case of S826, for wet ice conditions, it is about 5\%-10\% and 15\%-20\% for S832 profile section, whereas for the dry ice conditions, ice accumulation extends towards the chord length approximately up to $25 \%$ for S826 and S832 airfoil. This is useful information for design of anti/de-icing systems for the wind turbine blades consisting of S826 or S832 
airfoils. Numerical analysis of experimental iced profiles show a decrease in the aerodynamic characteristics of iced airfoils when it is compared with the clean airfoils. Changes in aerodynamic characteristics for S832 are higher than S826 particularly for wet ice conditions.

\section{Acknowledgement}

This work is supported by the University of Troms $\varnothing \mathrm{PhD}$ project [no- 381100/74104]. Authors would also like to acknowledge Mr. Pavlo Sokolov from UiT and Dr. David Hammond, Dr. Hugo Pervier and Mr. Peter West from Cranfield University, UK for assisting during icing tunnel experiments.

\section{References}

1. Neil Davis, Icing Impacts on Wind Energy Production. 2014, DTU: DTU Wind Energy.

2. Ozcan Yirtici, Ismail H.Tuncer, Serkan Ozgen, Ice Accretion Prediction on Wind Turbines and Consequent Power Losses. Journal of Physics: Conference Series, 2016. 753.

3. Katherine Bleich, R.D.Guimaraes, Renewable Infrastructure Investment Handbook: A Guide for Institutional Investors. 2016, World Economic Forum: Switzerland.

4. Sohrab Gholahosein Pouryoussefi, Masoud Mirzaei., Mohamed Mahdi Nazemi,Mojtaba Fouladi, Alreza Doostmahmoudi, Experimental study of ice accretion effects on aerodynamic performance of NACA23012 airfoil. Chinese Journal of Aeronautics, 2016. 29(3): p. 585-595.

5. Fayçal Lamraoui, Guy Fortin, Robert Benoit, Jean Perron and Christian Masson Atmospheric icing impact on wind turbine production. Cold Regions Science and Technology, 2014. 100: p. 14

6. I. Baring-Gould, L. Tallgaug, G. Ronsten, R. Hordaty, R. Cattin, R. Laakso, M. Durstewitz, A. Lacroix, E. Peltola, T. Wallenius, Recommendations for wind energy projects in cold climates. 2010, VTT Technical Research Center: Finland. p. 64.

7. Timo Laakso, Ian Baring-Gould, Michael Durstewitz, Robert Horbaty, Antoine Lacroix, Esa Peltola, Göran Ronsten, Lars Tallhaug, Tomas Wallenius, State-of-the-art of wind energy in cold climate,. 2010, VTT Technical Research Center: Finland. p. 71. 
8. R. Shaw, R. Sotos and F. solano, An Experimental Study of Airfoil Icing Characteristics, in Twentieth Aerospace Sciences Conference. 1982.

9. Jaiwon Shin, Thomas H. Bond, Results of an Icing Test on a NACA0012 Airfoil in the NASA Lewis Icing Research Tunnel, in 30th Aerospace Sciences Meeting and Exhibit. 1992: Reno, Nevada. p. 23.

10. Muhammad S. Virk, Matthew C.Homola, Per J. Nicklasson, Effect of Rime Ice Accretion on Aerodynamic Chracteristics of Wind Turbine Blade Profiles. Wind Engineering, 2010. 34(2): p. 207-218.

11. Matthew C. Homola, Muhammad S.Virk, Tomas Wallenius,Per J. Nicklasson,Per A. Sundsbø, Effect of atmospheric temperature and droplet size variation on ice accretion of wind turbine blades. Journal of

12. Matthew C. Homola, Muhammad S.Virk, Per J. Nicklasson and Per Arne Sundsbø, Performance losses

13. Jia Yi Jin, Muhammad S.Virk, Study of ice accretion along symmetric and asymmetric airfoils. Journal

14. Dan M. Somers, The S825 and S826 Airfoils. 1995: NREL.

15. Dan M. Somers, The S830, S831, and S832 Airfoils. 2002: NREL.

16. F. Bertagnolio, Niels N. Sørensen, Jeppe Johansen, P. Fuglsang, Wind turbine airfoil catalogue, DTU-

17. M. Etemaddar, Offshore Wind Turbine Operation under Atmospheric Icing and Controller System Faults.

18. Luca Oggiao, CFD simulations on the NTNU wind turbine rotor and comparison with experiments. in

19. Cranfield University. Icing Tunnel.

20. R Clift, J.R.Grace, M. e. Weber, Bubbles, drops and particles, 1978, New York. https://en.wikipedia.org/wiki/Bernoulli\%27s_principle. 